\title{
Sports Rehabilitation
}

Editor

JOE M. HART

\section{CLINICS IN \\ SPORTS MEDICINE}

www.sportsmed.theclinics.com

Consulting Editor

MARK D. MILLER

April 2015 - Volume 34 - Number 2 